\title{
Radiological Diagnosis
}

\section{Diagnosis of the case presented in the previous edition}

\section{J Bras Pneumol 2005;31(4):368.}

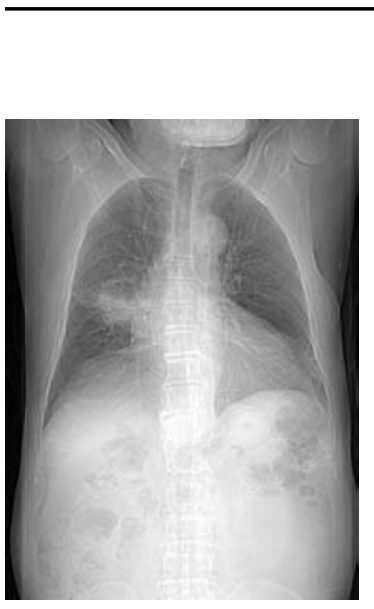

\section{PULMONARY ABSCESS}
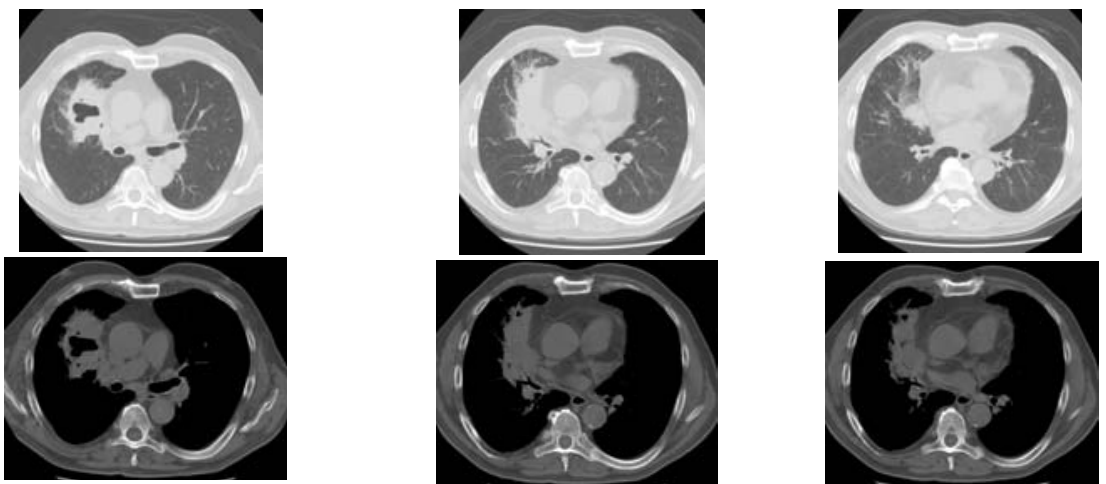

Male ex-smoker (40 pack/years),

complaining of productive cough, a 4-kg weight loss in 1 month and nocturnal fever $\left(37.4^{\circ} \mathrm{C}\right)$; no other symptoms.
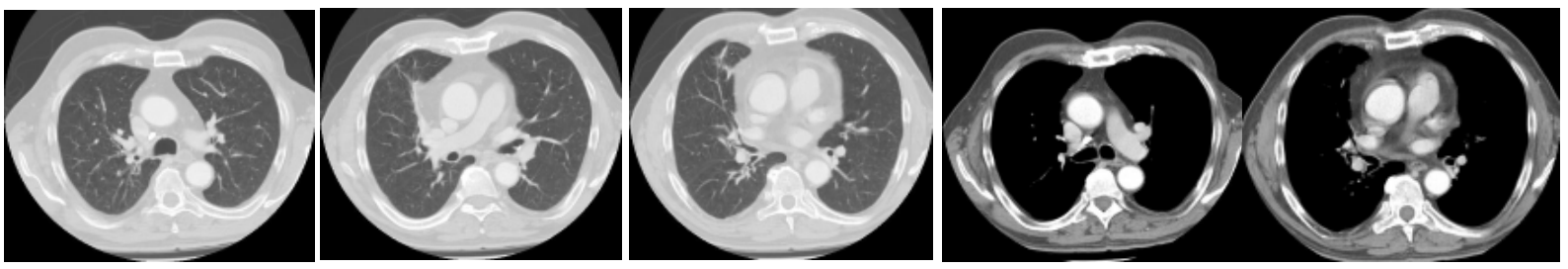

\section{COMMENTS}

In this oligosymptomatic smoker presenting a pulmonary mass accompanied by cavitation, the most probable diagnostic hypothesis is neoplasm. Therefore, bronchoscopy was ordered for this patient. The bronchoscopy only revealed inflammatory alterations in the bronchial tree, and transbronchial biopsies showed a nonspecific inflammatory process, with no sign of infectious agents.

Since neoplasm was not identified, empirical antibiotic therapy was initiated, and improvement of the symptoms was seen in the radiographic imaging - see the figures.

Pulmonary abscess is classically associated with symptoms resembling those of pneumonia: fatigue, loss of appetite, night sweats, fever, chest pain and productive cough in which the sputum may be streaked with blood and give off a foul odor. However, depending on the etiologic agent and the immune response of the patient, the profile may be one in which few symptoms are present, as illustrated in this case.

The radiographic and tomographic aspects of pulmonary abscess are similar and depend on the phase of the process. Initially, consolidations with ill-defined borders are observed. The process becomes increasingly more organized, culminating in the appearance of cavities. These cavities have thick, irregular walls and may present communication with the bronchial tree. An abscessed neoplasm appears identical to a pulmonary abscess, and there are no radiological signs sufficiently specific to differentiate between the two processes. The presence of air bronchograms in the cavity wall is a sign most frequently described in combination with abscesses, as in this case. 
DANY JASINOWODOLINSKI; GILBERTO SZARF; NESTOR L MÜLLER

Fleury Center for Diagnostic Medicine, São Paulo, São Paulo, Brazil, Universidade Federal de São Paulo (UNIFESP, Federal University of São Paulo), São Paulo, São Paulo, Brazil, University of British Columbia, Vancouver, British Columbia, Canada

\section{REFERENCES}

1. Marik PE. Aspiration pneumonitis and aspiration pneumonia. N Engl Med. 2001;344(9):665-71.
2. Kuhlman JE, Fishman EK, Teigen C. Pulmonary septic emboli: diagnosis with CT. Radiology. 1990;174(1):211-3.

3. Yang PC, Luh KT, Lee YC, Chang DB, Yu CJ, Wu HD, et al. Lung abscesses: US examination and US-guided transthoracic aspiration Radiology. 1991;180:(1)171-5.

4. Franquet T, Giménez A, Rosón N, Torrubia S, Sabaté JM, Perez C. Aspiration diseases: findings, pitfalls, and differential diagnosis Radiographics. 2000;20(3):67385.

5. Umemori Y, Hiraki A, Murakami T, Aoe K, Matsuda E, Makihara S, Takeyama H. Chronic lung abscess with Pasteurella multocida infection. Intern Med. 2005 Jul;44(7):754-6.

6. Bartlett JG. The role of anaerobic bacteria in lung abscess. Clin Infect Dis. 2005;40(7):923-5.

\section{READER(S) CORRECTLY DIAGNOSING THE CASE PRESENTED IN THE JULY/AUGUST 2005 ISSUE}

Ascedio José Rodrigues - Faculdade de Medicina da Universidade de São Paulo - São Paulo - SP

Carlos Jardim - Hospital das Clínicas da Faculdade de Medicina da Universidade de São Paulo - São Paulo - SP

Petrucio Abrantes Sarmento - Universidade Federal de São Paulo - São Paulo - SP

Ruben Urdaneta - Hospital Domingo Luciano - Caracas - Venezuela 